\title{
Role of Visual Inspection of Cervix with Acetic Acid (VIA) in Detecting Precancerous Lesions of Cervix
}

\author{
Kamrun Nessa ${ }^{1}$, Khadija Nazneen ${ }^{2}$, Najnin Munni $^{3}$, Runa Laila ${ }^{4}$, Farhana Islam ${ }^{5}$, Sheikh Rabeya Akhter ${ }^{6}$ \\ Received: January 18, 2013 Accepted: August 21, 2013
}

\begin{abstract}
Background: Carcinoma of cervix is the most common malignancy in female and a major public health problem worldwide. It is the leading cause of death from cancer among women in low resource settings. In Bangladesh, mortality rate is high as most of the cases with cervical cancer are diagnosed in advanced stage. World Health Organization considers cervical cancer as a preventable disease as it can be identified in preinvasive stage. Considerable efforts have been given in detection and treatment of the condition all over the world. A number of cervical cancer screening tests are available. Among them, visual inspection of cervix with acetic acid is rational and can be competently performed by physicians with proper training. Objective: To find out the feasibility of the visual inspection of cervix with acetic acid for the detection of the precancerous lesions of the cervix in our country. Materials and Methods: This cross sectional, analytical study was carried out among the patients attending the outpatient department of Bangabandhu Sheikh Mujib Medical University (BSMMU) who were VIA positive and sent for colposcopy in the colposcopy clinic in the department of Obstetrics and Gynecology in BSMMU from June to December 2004. Two hundred samples were considered for this study. Results: Out of 200 cases, colposcopically $85 \%$ had CIN and invasive lesions, $4 \%$ had inflammatory lesions while $11 \%$ had normal findings. Colposcopy directed punch biopsy revealed positive lesions in $81 \%$, 4\% had inflammatory lesions while 15\% had normal findings. Conclusion: The study concluded that VIA and colposcopy are the important methods in the evaluation of cervical premalignancy. VIA may be an important tool for screening of cervical cancer in low resource settings as it is simple, easy to perform and cost-effective. After screening, VIA positive cases must be referred for colposcopic evaluation. We can screen cervical cancer by VIA all over the country and thus reduce morbidity and mortality rate.
\end{abstract}

Key words: VIA, Cervical cancer, Colposcopy, Cervical intraepithelial neoplasia

J Enam Med Col 2014; 4(1): 39-44

\section{Introduction}

Cervical cancer is a preventable and also a curable disease, preventable by screening of cervix and curable, if identified at an early stage. ${ }^{1}$ Carcinoma of the cervix is the most common malignancy in female and a major public health problem worldwide. It comprises approximately $12 \%$ of all cancers in women. It is the second most common cancer in women worldwide, but the commonest in the developing countries. ${ }^{1}$ It is the leading cause of death from cancer among women in low resource settings. ${ }^{1}$ About 500,000 new cases are identified each year and at least 200,000 women die of this

1. Associate Professor, Department of Obstetrics \& Gynecology, Enam Medical College \& Hospital, Savar, Dhaka

2. Professor, Department of Obstetrics \& Gynecology, Enam medical College \& Hospital, Savar, Dhaka

3. Assistant Professor, Department of Obstetrics \& Gynecology, East West Medical College \& Hospital, Dhaka

4. Assistant Professor, Department of Obstetrics \& Gynecology, Nightingale Medical College \& Hospital, Dhaka

5. Assistant Registrar, Department of Obstetrics \& Gynecology, Enam Medical College \& Hospital, Savar, Dhaka

6. Assistant Registrar, Department of Obstetrics \& Gynecology, Enam Medical College \& Hospital, Savar, Dhaka

Correspondence Kamrun Nessa, Email: knessa3@yahoo.com 
cancer each year. Eighty percent of the new cases occur in the developing countries, while this is declining in the developed world due to introduction of different screening tests. In Southeast Asia and Africa, where women live in poor condition, the incidence and mortality rate of carcinoma cervix may be 4 or 5 times higher than those seen in developed countries. ${ }^{2}$

No reliable statistical data about cancer are available for most developing countries in general and Bangladesh in particular. However, cancer is one of the leading causes of morbidity and mortality in Bangladesh. ${ }^{3}$ Most of the cervical cancers are diagnosed in the advanced stage, so mortality is high. Based on the world health statistics, new cancer cases in Bangladesh have been estimated at 167 per 100,000 populations. An epidemiological institute of cancer research of Bangladesh (1976-83) showed that the prevalence of cancer cervix is $26 \%$ amongst all types of cancers affecting female. ${ }^{4}$ The prevention and control of cancer in developing countries deserve urgent attention since the disease is likely to double in these countries in the next 20-25 years. The problem of cancer in Bangladesh is acute because of poverty, early age of marriage, multiple marriages, high parity, illiteracy and other diseases associated with poor nutrition and lack of basic knowledge of the people about health matters. Therefore, understanding the etiological factors is important for the successful prevention of the disease. ${ }^{5}$ World Health Organization (WHO) considers cervical cancer as a preventable disease. $^{5}$ This is because cervix is easily accessible, the disease has a long premalignant phase and can be diagnosed in its precancerous stage. As it is preventable and almost curable when diagnosed early, that is, in its preinvasive stage (cervical intraepithelial neoplasia [CIN]), considerable efforts have been given in detecting and treating the condition all over the world. The decrease in cervical cancer prevalence in most of the developed countries is attributed to the success of cytology based screening program, but our country often lacks the necessary resource to use the pap smear as a screening tool for cervical abnormalities. ${ }^{6}$ As the incidence of cervical cancer is highest in low resource settings, alternative techniques have been sought. Recently, visual inspection with acetic acid (VIA) has gained popularity. ${ }^{7}$

In some developed and developing countries, cervical cytology test for carcinoma of cervix and CIN has become a routine procedure. WHO suggested an alternative to regular cytologic screening known as "down staging screening" as an experimental approach. It can be defined as the detection of the disease at an earlier stage by nurses and other nonmedical health personnel using a simple speculum for visual inspection of the cervix. ${ }^{8}$

In Bangladesh, where prevalence of cancer is high and cytological screening is not available, down staging screening may be useful. This approach must be coupled with cytological screening. But cytology also cannot determine the extent or location of abnormality though it is highly accurate in detecting the presence of cervical neoplasia. ${ }^{9}$

Available cervical cancer screening tests are automated pap screening, visual inspection with acetic acid, human papilloma virus testing and the recently introduced polar probe. Among these visual inspection with acetic acid is the most suitable test because it is rational for low resource setting as it is inexpensive and usually locally available, gives immediate result, can be competently performed by physicians with proper training and drop-out during follow-up is minimal. ${ }^{10,11}$ The aim of this study was to find out the role of VIA for the detection of precancerous and early cancerous lesions of the cervix with the ultimate objective to assess whether VIA could be used as a mass screening test as an alternative to cytology.

\section{Material and Methods}

This cross sectional, analytical study was carried out among 200 VIA positive patients, attending the outpatient department of Gynecology and Obstetrics of Bangabandhu Sheikh Mujib Medical University (BSMMU) and sent for colposcopy in the 'colposcopy clinic'. The period of study was from June to December 2004. Married women, aged 18-60 years with signs and symptoms of early cervical cancer were included in the study. Menstruating women, patients with obvious growth or big mass in the cervix, pregnant and hysterectomized women were excluded. 
A speculum was introduced into the vagina and cervix was exposed under good light source. A cotton ball soaked with 3-5\% acetic acid was applied on the cervix and retained for one minute. Then the cotton ball was removed. Abnormal cells on the cervix temporarily turned white indicating acetowhite epithelium on the cervix (VIA positive). Women with acetowhite lesions were considered for colposcopic examination and biopsy.

Colposcopy findings and colposcopy directed biopsy findings of study subjects were compared to find out the effectiveness of VIA as a mass screening test to detect precancerous lesions of cervix.

\section{Results}

The age of the patients was between 18-60 years with mean \pm SD $36.4 \pm 9.8$. About $75 \%$ were housewives, among them $60 \%$ maintained personal hygiene. Among the husbands of the patients $37 \%$ were businessmen, $26.5 \%$ were government service holders, $12.5 \%$ farmers, $8 \%$ rickshaw pullers and $2.5 \%$ had jobs abroad. Seventy four percent patients lived in urban area and $26 \%$ in rural area.

Table I shows the menstrual history of the study subjects. Among them 180 had continued menstruation; 33\% patients had irregular menstruation and $67 \%$ cases had regular menstruation with average flow and duration. Intermenstrual bleeding was found in $27.78 \%$ cases while it was absent in $72.22 \%$ cases.

Table II shows the length of marital period and obstetric history. About $10 \%$ patients had married life for $<10$ years, $23 \%$ for $10-15$ years, $32 \%$ for $16-20$ years, $20 \%$ for $20-25$ years, $10 \%$ for $26-30$ years and $5 \%$ had $31-35$ years with mean \pm SD $18.3 \pm 6.8$. Eight patients had no children and $17 \mathrm{had} \geqslant 5$ children.

Table III shows that the hormonal contraceptives, barrier and both methods were used by $60 \%, 21.5 \%$ and $18.5 \%$ cases respectively. Regarding history of exposure, $85 \%$ had no extramarital exposure and $15 \%$ had history of exposure. Family history of cancer was absent in $97.5 \%$ cases while only $2.5 \%$ had it. More than $56.5 \%$ had first coitus at the age of 14 to 17 years, $20 \%$ before 14 and $23.5 \%$ after 17 years. There was no smoker among the respondents.
Table IV shows the clinical features of the study subjects. Forty percent of the cases had no symptoms at all. Dirty brown or white excessive vaginal discharge was the complaint of more than $50 \%$ of the cases. Dyspareunia, backache, dysuria, postcoital bleeding, abnormal intermenstrual bleeding and heavy irregular vaginal bleeding were in $20 \%, 15 \%$, $10 \%, 10 \%, 7.5 \%$ and $2.5 \%$ cases respectively.

Table $\mathrm{V}$ shows that $85 \%$ had apparently healthy cervix in speculum examination. Cervical erosion was noted in $12.5 \%$ cases. Bimanual examination showed $86 \%$ had normal findings and $14 \%$ had abnormal findings - $4 \%$ had soft cervix, $5 \%$ had firm to hard cervix and $5 \%$ bled on touch.

Table VI shows colposcopic and colposcopy directed biopsy findings of study subjects. Colposcopy showed that $11 \%$ cases had healthy cervix, $4 \%$ had inflammation, 58\% CIN I, 14\% CIN II, 10\% CIN III and $3 \%$ had cervical carcinoma. Colposcopy directed biopsy findings showed that $78 \%$ had CIN $-52.5 \%$ CIN I, 17\% CIN II and 8.5\% CIN III. Carcinoma cervix was found in $3 \%$ cases.

Table I: Menstrual history of the study subjects

\begin{tabular}{|c|c|c|}
\hline Variables & Frequency & Percentage \\
\hline \multicolumn{3}{|c|}{ Menstruation $(n=200)$} \\
\hline Cessation & 20 & 10 \\
\hline Continued & 180 & 90 \\
\hline \multicolumn{3}{|c|}{ Period of menstruation $(n=180)$} \\
\hline 2-3 days & 20 & 11.11 \\
\hline 4-5 days & 80 & 44.44 \\
\hline 6-7days & 20 & 11.11 \\
\hline Irregular & 60 & 33.33 \\
\hline \multicolumn{3}{|c|}{ Menstrual flow $(n=180)$} \\
\hline Scanty* & 15 & 8.33 \\
\hline Average** & 140 & 77.77 \\
\hline Excessive ${ }^{* * *}$ & 25 & 13.88 \\
\hline \multicolumn{3}{|c|}{ Intermenstrual bleeding $(n=180)$} \\
\hline No & 130 & 72.22 \\
\hline Yes & 50 & 27.78 \\
\hline
\end{tabular}

*few drops/day ** clot absent $* * *$ clot present 
Table II: Length of marital period and obstetric history of the study subjects $(\mathrm{n}=200)$

\begin{tabular}{l|c|c|}
\hline $\begin{array}{l}\text { Variables } \\
\text { Married for }\end{array}$ & Number & Percentage \\
\hline$<10$ years & 20 & 10 \\
10-15 years & 46 & 23 \\
16-20 years & 64 & 32 \\
21-25 years & 40 & 20 \\
26-30 years & 20 & 10 \\
31-35 years & 10 & 5 \\
Mean \pm SD is $18.3 \pm 6.8$ & & \\
Para & & \\
None & 08 & 4.0 \\
Up to 2 & 82 & 41.0 \\
2-4 & 93 & 46.5 \\
$\geqslant 5$ & 17 & 8.5 \\
Mean \pm SD is $2.8 \pm 1.4$ & & \\
\hline
\end{tabular}

Table III: Risk factors of cervical cancer among study subjects $(\mathrm{n}=200)$

\begin{tabular}{|l|c|c|}
\hline Risk factors & Number & Percentage \\
\hline \begin{tabular}{l|c} 
Contraceptive methods used \\
Barrier
\end{tabular} & 43 & 21.5 \\
\hline Hormonal & 120 & 60.0 \\
\hline $\begin{array}{l}\text { Both } \\
\text { History of extramarital exposure }\end{array}$ & 37 & 18.5 \\
\hline No & 170 & 85.0 \\
\hline Yes & 30 & 15.0 \\
\hline Family history of cancer & & \\
\hline Yes & 5 & 2.5 \\
\hline No & 195 & 97.5 \\
\hline
\end{tabular}

Table IV: Clinical features of study subjects $(n=200)$

\begin{tabular}{|l|c|c|}
\hline Clinical features & Number & Percentage \\
\hline None & 80 & 40 \\
\hline Abnormal intermenstrual bleeding & 15 & 7.5 \\
\hline Postcoital bleeding & 20 & 10 \\
Excessive vaginal discharge & 110 & 55 \\
Heavy irregular vaginal bleeding & 5 & 2.5 \\
Backache & 30 & 15 \\
Dysuria & 20 & 10 \\
Dyspareunia & 40 & 20 \\
\hline
\end{tabular}

Some patients had multiple presentations
Table V: Speculum and bimanual examination findings of the study subjects $(\mathrm{n}=200)$

\begin{tabular}{|c|c|c|}
\hline & Frequency & Percentage \\
\hline \multicolumn{3}{|l|}{ Speculum findings } \\
\hline Apparently healthy cervix & 170 & 85 \\
\hline Erosion & 25 & 12.5 \\
\hline Nodular & 2 & 1 \\
\hline Ulcer & 3 & 1.5 \\
\hline $\begin{array}{l}\text { Bimanual examination } \\
\text { Uterus }\end{array}$ & & \\
\hline Normal & 180 & 90 \\
\hline Abnormal & 20 & 10 \\
\hline Fornix & & \\
\hline Normal & 184 & 92 \\
\hline Abnormal & 16 & 8 \\
\hline Normal & 172 & 86 \\
\hline Abnormal & 28 & 14 \\
\hline
\end{tabular}

Table VI: Colposcopic and colposcopy directed biopsy findings $(n=200)$

\begin{tabular}{|l|c|c|}
\hline \multicolumn{1}{|l|}{$\begin{array}{l}\text { Colposcopy findings } \\
\text { Squamocolumnar junction }\end{array}$} & & \\
\hline $\begin{array}{l}\text { Visualized } \\
\text { Not clear }\end{array}$ & 168 & 84 \\
$\begin{array}{l}\text { Punctation site (acetowhite lesion) } \\
\text { Upper lip }\end{array}$ & 32 & 16 \\
Lower lip & 156 & 78 \\
Findings proper & 24 & 12 \\
Normal & & \\
Inflammation & 22 & 11 \\
CIN I & 8 & 4 \\
CIN II & 116 & 58 \\
CIN III & 28 & 14 \\
Invasive carcinoma & 20 & 10 \\
Colposcopy directed biopsy findings & 6 & 3 \\
Normal & 30 & \\
Inflammation & 8 & 15 \\
CIN I & 105 & 4 \\
CIN II & 34 & 52.5 \\
CIN III & 17 & 17 \\
Invasive carcinoma & 6 & 8.5 \\
\hline
\end{tabular}

Sensitivity and specificity analysis

As all the cases were VIA positive, the sensitivity and specificity could not be analyzed. But the sensitivity and specificity of colposcopy were calculated considering colposcopy directed biopsy as gold standard. VIA test was positive in $100 \%$ cases as the study planned, among them $85 \%$ cases were positive by colposcopy and $81 \%$ cases were positive in biopsy. The sensitivity and specificity of colposcopy were $92.59 \%$ and $47.36 \%$ respectively (Table VII). 
Table VII: Diagnostic efficacy of colposcopy

\begin{tabular}{|c|c|c|c|}
\hline \multirow[t]{2}{*}{ Colposcopy findings } & \multicolumn{2}{|c|}{ Colposcopy directed biopsy } & \multirow[t]{2}{*}{ Total } \\
\hline & Positive & Negative & \\
\hline Positive & 150 & 20 & 170 \\
\hline Negative & 12 & 18 & 30 \\
\hline Total & 162 & 38 & 200 \\
\hline Sensitivity & \multicolumn{2}{|c|}{$92.59 \%$} & \\
\hline Specificity & \multicolumn{2}{|c|}{$47.36 \%$} & \\
\hline Accuracy & \multicolumn{2}{|c|}{$84 \%$} & \\
\hline Positive predictive va & \multicolumn{2}{|c|}{$88.24 \%$} & \\
\hline Negative predictive $\mathrm{v}$ & \multicolumn{2}{|c|}{$60 \%$} & \\
\hline
\end{tabular}

\section{Discussion}

The present study was carried out to determine the role of VIA and colposcopy in the diagnosis of cervical intraepithelial neoplasia and to determine whether VIA may be used as a screening test in the diagnosis of precancerous lesions of cervix.

In this study, more than two-thirds of the cases were between $36-45$ years of age. Sayeeda $\mathrm{S}^{12}$ in her study found about $32 \%$ in $36-45$ years and $38.46 \%$ in the age of $26-35$ years. Toffazzal $\mathrm{N}$ et $\mathrm{al}^{13}$ found maximum cases in 40-50 years age group closely followed by $30-40$ years, where the age of incidence of invasive cervical cancer was $40-45$ years. The findings of these studies indicate that CIN is more prevalent in sexually active women. WHO also emphasized screening in the age group 35-45 years. ${ }^{8,10}$

In this study most of the cases were housewives followed by garments workers, service holders and students. About one-third of the cases had unsatisfactory personal hygiene. In this study most of the cases were from urban area. This may be due to the awareness among the urban population and location of the institution where the study was done in urban area.

In our study, $55 \%$ respondents had $>2$ children which indicates that multiparity may be a related risk for premalignancy of the cervix. In the present study highest percentage had experienced menarche at the age of 13 years. Among 180 menstruating subjects, $33 \%$ had irregular menstruation. Among subjects with regular menstrual history, $80(44.4 \%)$ had 4-5 days cycle and $140(77.7 \%)$ had average menstrual flow.
In our study there were no smokers among the study subjects, therefore we could not assess the risk of smoking on cervical premalignancy. In this study we found that $15 \%$ cases had multiple sexual partners. Among the study subjects $60 \%$ were hormonal contraceptive users which is higher than the nationwide data $(53.8 \%)$. This indicates that the use of contraceptives is higher in the CIN cases. Regarding age of first coitus, $76.5 \%$ experienced coitus before 18 years. Sayeeda $\mathrm{S}^{12}$ found that more than $80 \%$ had experienced first coitus before 19 years. Only $2.5 \%$ had family history of cancer in this study.

In this study, most common presentations were excessive vaginal discharge, backache, dysuria and dyspareunia. All these were non-specific, which indicated the need for screening test to diagnose CIN. Forty percent subjects had no symptoms or signs. By speculum examination of 200 cases, 172 $(86 \%)$ had normal appearance of cervix.

In this study, colposcopically $85 \%$ had CIN and invasive lesions, while $15 \%$ had normal or inflammatory lesions. Colposcopically directed punch biopsy revealed $81 \%$ cases showed positive lesions and $19 \%$ had no lesions or CIN.

As all of the cases were VIA positive, the sensitivity and specificity of VIA could not be calculated. But considering CDB as a gold standard, the sensitivity and specificity of colposcopy were $92.59 \%$ and $47.36 \%$ respectively. Among 200 cases, $85 \%$ were positive by colposcopy. In CDB $81 \%$ had positive finding. Therefore, it stands that $19 \%$ was false positive VIA test in comparison with $\mathrm{CDB}$. The false negative could not be calculated as all the cases were VIA positive.

The study concludes that VIA and colposcopy are the important methods in the evaluation of cervical premalignancy. VIA may be an important tool for screening cervical cancer in low resource settings as it is a simple method, easy to perform and costeffective. VIA may be associated with a referral procedure for further methods. Cervical cancer is a priority concern for the WHO program on cancer control. WHO recommends and emphasizes on programs for early detection with a systematic approach and that can be well-integrated into the existing health system. 


\section{References}

1. Sellers J, Lewis K, Kidula N, Muhombe K, Tsu V, Herdman C. Screening and management of precancerous lesions to prevent cervical cancer in low resource settings. Cervical cancer prevention group. Asian Pac J Cancer Prev 2003; 4(3): 277-280.

2. Jeffcoate N. Tumours of the cervix uteri. In: Bhatla $\mathrm{N}$ (ed). Jeffcoate's principles of gynaecology. $6^{\text {th }}$ edn. London: Butterworth-Heinemann Ltd., 2001: 444-465.

3. Sultana F. Incidence of CIN in a group of patients presenting with clinically unhealthy cervix [MS thesis]. Dhaka: Bangabandhu Sheikh Mujib Medical University; 1996.

4. The prevention and control of cervical cancer in developing countries. Available at: www.bangla pedia.org/HT/C-0033.HTM. Accessed January 2013.

5. Illancheran A. Screening for cervical cancer. In: Ratnam SS, Rao KB, Arulkumaran S (eds). Obstetrics \& gynecology for postgraduates (Vol II). $2^{\text {nd }}$ edn. India: Orient Longman Ltd, 1994; 328-338.

6. Belinson JL, Pretotrius RG, Zhang WH, Qiao YL, Elson P. Cervical cancer screening by visual inspection with acetic acid. Obstet \& Gynecol. 2001; 98: 441-444.

7. Gaffikin L, Lauterbatch M, Blumenthal PD. Performance of visual inspection with acetic acid for cervical cancer screening: a qualitative summary of evidence to date. Obstet \& Gynecol Surv. 2003; 58(8): 543-550.
8. Chowdhury NNR. Diagnosis and treatment of cervical cancer. In: Ratnam SS, Rao KB, Arulkumaran S (eds). Obstetrics \& gynecology for postgraduates (Vol I). $2^{\text {nd }}$ edn. India: Orient Longman Ltd, 1999: 380-394.

9. Srisomboon J, Tangchitrong CA, Bhuswang Y, Chairatana A. Evaluation of colposcopic accuracy in diagnosis of cervical neoplasia. J Med Assoc Thai 1996; 79(7): 423-427.

10. World Health Organization, Pan-America Health Organization. Visual inspection of the uterine cervix with acetic acid (VIA) for cervical cancer - cancer screening. Available at: www.Paho.Org/english/ $\mathrm{ad} / \mathrm{dpc} / \mathrm{nc}-\mathrm{cc}-\mathrm{via} . \mathrm{htm}$. Accessed November 2004.

11. Gaffikin L, Blumenthal PD, Emerson M, Limpaphayom K. Royal Thai College of Obstetrics \& Gynecology (RTCOG) and The JHPIEGO Corporation Cervical Cancer Prevention Group. Safety, acceptability and feasibility of a single visit approach to cervical cancer prevention in rural Thailand: a demonstration project. The Lancet 2003; 361(9360): 814-820.

12. Sayeeda S. Colposcopic findings in clinically unhealthy cervix: a study in a group of patients attending colposcopy clinic at BSMMU [FCPS Dissertation]. Dhaka: Bangladesh College of Physicians and Surgeons; 2003.

13. Tofazzal N, Khan BR, Islam B, Mohsin A, Quddus R. Study of the association of human papiloma virus with cervical cancer and precancerous lesions in a group of Bangladeshi women. J Bangladesh Coll Phy Surg 1994; 12(1): 85-88. 